\title{
Challenges in early phase clinical trials for childhood cancer during the COVID-19 pandemic: a report from the new agents group of the Spanish Society of Paediatric Haematology and Oncology (SEHOP)
}

\author{
A. Rubio-San-Simón ${ }^{1} \cdot$ J. Verdú-Amorós ${ }^{1} \cdot$ R. Hladun ${ }^{2} \cdot$ A. Juan-Ribelles ${ }^{3} \cdot$ M. Molero ${ }^{4} \cdot$ P. Guerra-García ${ }^{5}$.

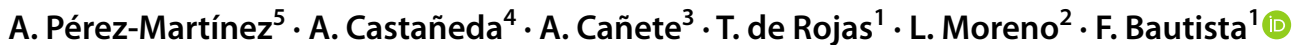

Received: 5 May 2020 / Accepted: 12 May 2020 / Published online: 29 May 2020

(c) Federación de Sociedades Españolas de Oncología (FESEO) 2020

\begin{abstract}
Purpose The COVID-19 pandemic has forced healthcare stakeholders towards challenging decisions. We analyse the impact of the pandemic on the conduct of phase I-II trials for paediatric cancer during the first month of state of alarm in Spain. Methods A questionnaire was sent to all five ITCC-accredited Spanish Paediatric Oncology Early Phase Clinical Trial Units, including questions about impact on staff activities, recruitment, patient care, supply of investigational products, and legal aspects.

Results All units suffered personnel shortages and difficulties in enrolling patients, treatment continuity, or performing trial assessments. Monitoring activity was frequently postponed (73\%), and 49\% of on-going trials interrupted recruitment. Only two patients could be recruited during this period ( $75 \%$ reduction in the expected rate).

Conclusions The COVID-19 crisis has significantly impacted clinical research practice and access to innovation for children with cancer. Structural and functional changes are under way to better cope with the expected future restrictions.
\end{abstract}

Keywords COVID-19 · Clinical trials · Clinical research · Paediatric haematology and oncology $\cdot$ Development policy

\section{Purpose}

The COVID-19 pandemic has affected more than 3 million people worldwide and 25,000 have died in Spain as of 2nd May 2020 [1] and healthcare stakeholders have taken

F. Bautista

franciscojose.bautista@salud.madrid.org

A. Rubio-San-Simón

franciscojose.bautista@salud.madrid.org

1 Division of Paediatric Haematology and Oncology, Hospital Universitario Niño Jesús, Madrid, Spain

2 Division of Paediatric Haematology and Oncology, Hospital Universitari Vall D`Hebron, Barcelona, Spain

3 Division of Paediatric Haematology and Oncology, Hospital Universitario y Politécnico La Fe, Valencia, Spain

4 Division of Paediatric Haematology and Oncology, Hospital Sant Joan de Déu, Barcelona, Spain

5 Division of Paediatric Haematology and Oncology, Hospital Universitario La Paz, Madrid, Spain challenging decisions to safeguard public health. In Spain, on March 14th, the government declared the state of alarm [2]. As a consequence, the Spanish healthcare system has suffered unprecedented adjustments to prioritize resources for the fight against COVID-19 [3]. Outpatient follow-up and elective procedures have been cancelled and healthcare providers reallocated to assist patients with COVID-19.

Although SARS-CoV-2 is suspected to infect children milder than adults [4], adjustment of healthcare facilities has been established also for them $[5,6]$.

The countermeasures adopted by the authorities can impact hardly in clinical research, which often is perceived as a "desirable but not essential" activity. Actions undertaken can affect the conduct of clinical trials in many ways [e.g., completion of trial assessments, visits, and provision of investigational medicinal products (IMPs)]. Furthermore, pharmaceutical companies may refocus resources into areas related to COVID-19 (e.g., vaccines or antiviral drugs), thus affecting other research areas. 
This situation forces sponsors, investigators, and patients to adapt. The European Medicines Agency and the Spanish Agency of Medicines and Medical Devices have issued guidelines on the management of clinical trial activities $[7,8]$ Both are aligned in the intention to guarantee trial activity, patient safety, and action traceability. However, all parties (i.e., healthcare authorities, hospitals, regulators, and sponsors) have implemented measures differently depending on the impact of the pandemic in their regions and their capacity to adapt, although not all coordinated nor evidence-based.

Cancer research is particularly challenging, because patients are remarkably vulnerable: their baseline condition needs close surveillance and delays in diagnosis or treatment are potentially fatal [9]; in parallel, cancer patients are at increased risk for severe COVID-19 disease [10-12]

We evaluated the impact of the COVID-19 pandemic on the early phase clinical trial activity in paediatric oncology during the first month of state of alarm in Spain (14th March-12th April 2020).

\section{Methods}

In Spain, the Innovative Therapies for Children with Cancer consortium (ITCC), an international scientific organisation dedicated to early drug development for childhood cancers in 56 centres from 14 European countries, has accredited five paediatric cancer centres to deliver early phase clinical trials [13]. All five centres were contacted and sent a 93-item questionnaire between 13th and 19th April 2020 investigating the impact of the pandemic on actively recruiting phase I-II clinical trials in solid and haematological paediatric malignancies and on molecular cancer platforms (Appen$\operatorname{dix} I)$.

Descriptive statistics of the survey are provided.

\section{Results}

\section{Impact on staff}

All units suffered shortages on on-site staff in all professional strata (Table 1). The median decrease in personnel was 59\% (range 33-100). Main causes were: institutional contingency policies (88\%), COVID-19-infected workers (7\%), and relocation to other hospital areas (5\%).

All units managed to perform remote data entry, although two were not fully equipped for and had difficulties to perform their activities.

\section{Impact on on-site activities performed by the sponsors}

Seventy percent (7/10) planned site initiation visits (SIV) were postponed and $30 \%(n=3)$ were performed remotely, all as per decision of the sponsor.

Seventy-three percent (36/49) planned monitoring visits (MV) which were postponed and 27\% $(n=13)$ were performed remotely, mostly due to institutional decision $(70 \%)$.

\section{Impact on recruitment}

The median number of studies that stopped recruitment per site was 6 (range 2-6), a 49\% on average (SD 32.5) of actively recruiting studies. The decision to stop was taken per sponsor $(47 \%)$ or per local institutions $(53 \%)$. One unit interrupted recruitment in all trials $(n=18)$ following institutional decision. During this period, only two new patients were enrolled across the whole of Spain, $75 \%$ less than the monthly average in $2019(n=8)$.

\section{Impact on organization of patient care}

All units continued on-site patient care with limitations. Two units had restrictions to perform assessments due to local prevention strategies.

Out of 143 planned patient visits, 15 (10\%) had to be rescheduled. Most were conducted on-site $(77 \%, 110)$, while $14 \%$ (20) were conducted by phone and $9 \%$ (13) in other hospitals closer to family home. Only one patient experienced treatment delay (parents' decision).

Seven patients that were potentially eligible could not be enrolled. Of those, four received non-trial treatments and three are on standby. The reasons for not enrolling were: recruitment interrupted by sponsor $(n=3)$ and not considered safe to be included by investigators $(n=4)$

\section{Impact on supply of investigational medicinal product and research devices}

Provision of IMPs and research devices, as well as shipment of research samples, were uniformly warranted. For six trials, two units were able to ship IMPs to patients' homes or to local hospitals. Three units provided larger amounts of trial medications to patients to minimise hospital visits.

\section{Impact on legal and regulatory aspects}

The completion of three planned contracts was delayed. All units have been provided with contingency plans by 
Table 1 Summary of responses to the survey provided by the five early phase clinical trials units

Items Total, $n \quad$ Total, $\% * *$

Baseline data*

$\begin{array}{lr}\text { Phase I trials active, recruiting } & 27\end{array}$

$\begin{array}{lr}\text { Phase II trials active, recruiting } & 57\end{array}$

Molecular platforms active, recruiting $\quad 2$

Total phase I-II trials or molecular platforms active, recruiting $\quad 86$

$\begin{array}{ll}\text { H Vall d'Hebron } & 25\end{array}$

$\begin{array}{ll}\text { H Sant Joan de Deu } & 8\end{array}$

$\begin{array}{ll}\mathrm{H} \mathrm{LaFe} & 18\end{array}$

$\begin{array}{ll}\mathrm{H} \mathrm{La} \mathrm{Paz} & 9\end{array}$

$\begin{array}{ll}\text { H Niño Jesús } & 26\end{array}$

$\begin{array}{lr}\text { Phase I trials active, not yet recruiting } & 8\end{array}$

$\begin{array}{ll}\text { Phase II trials active, not yet recruiting } & 8\end{array}$

SIV previously scheduled for March/April 2020 10

MV previously scheduled for March/April $2020 \quad 49$

$\begin{array}{lr}\text { Unit's full-time workers } & 73\end{array}$

$\begin{array}{ll}\text { Total of patients recruited in Phase I/II studies during } 2019 & 98\end{array}$

Impact on personnel

Number of units suffering shortages of on-site staff

$100 \%(5 / 5)$

Total reduction in number of on-site workers

Cause of personnel reduction:

COVID-19-infected workers

Institutional contingency policy (i.e., home-based work)

Relocation to other areas to work on COVID-19

Units performing remote data entry

Units with appropriate tools for homeworking

Impact on on-site activities performed by the sponsors

Units suffering SIV delays/cancellation

$60 \%(3 / 5)$

Number of SIV postponed

$80 \%(4 / 5)$

Postponing SIV decided by:

\section{Sponsor}

Investigators

Institution

Number of SIV performed remotely

Units suffering MV delays/cancellation

Number of MV postponed

$70 \%(7 / 10)$

Postponing MV decided by:

Institution

Investigators

Sponsor + Institution

Number of MV performed remotely

$100 \%(7 / 7)$

$0 \quad 0 \%$

$0 \quad 0 \%$

$3 \quad 30 \%(3 / 10)$

$5 \quad 100 \%(5 / 5)$

$36 \quad 73 \%(36 / 49)$

Impact on recruitment

Units continuing recruitment

Units with restrictions to accept new referrals

New patients recruited to early phase trials***

Trials with recruitment stopped

H Vall d'Hebron

H Sant Joan de Deu

$\mathrm{H} \mathrm{La} \mathrm{Fe}$

H La Paz 
Table 1 (continued)

\begin{tabular}{|c|c|c|}
\hline Items & Total, $n$ & Total, \%** \\
\hline \multicolumn{3}{|l|}{ Recruitment stop decided by: } \\
\hline Sponsor & 18 & $47 \%(18 / 38)$ \\
\hline Investigators & 0 & $0 \%$ \\
\hline Institution & 20 & $53 \%(20 / 38)$ \\
\hline \multicolumn{3}{|l|}{ Impact on IMP and research devices } \\
\hline Trials with IMP shortages & 0 & $0 \%$ \\
\hline Units shipping IMPs to the patient's home or to the local healthcare institution & 2 & $40 \%(2 / 5)$ \\
\hline Trials in which IMP were shipped to the patient's home or to the local healthcare centres & 6 & $7 \%(6 / 84)$ \\
\hline Units in which the sponsor facilitated the shipment of IMP to patients & 5 & $100 \%(5 / 5)$ \\
\hline Units managing to increase IMP supplies to patients & 3 & $60 \%(3 / 5)$ \\
\hline Trials managing to increase IMP supplies to patients & 15 & $18 \%(15 / 84)$ \\
\hline Trials suffering shortages of research devices (e.g., sample kits) & 0 & $0 \%$ \\
\hline Units with difficulties to send out research samples & 0 & $0 \%$ \\
\hline \multicolumn{3}{|l|}{ Impact on patient care organization } \\
\hline Units suffering restrictions to treat patients & 5 & $100 \%(5 / 5)$ \\
\hline Total number of patient visits conducted & 143 & \\
\hline Patient visits conducted on-site & 110 & $77 \%(110 / 143)$ \\
\hline Patient visits conducted in other healthcare facilities & 13 & $9 \%(13 / 143)$ \\
\hline Patient visits conducted by phone & 20 & $14 \%(20 / 143)$ \\
\hline Patient visits rescheduled & 14 & $10 \%(14 / 143)$ \\
\hline Patient visits cancelled & 0 & $0 \%$ \\
\hline Units which received sponsor's agreement to conduct patient visits in other health care institutions & 5 & $100 \%(5 / 5)$ \\
\hline Patients suffering treatment delays & 1 & \\
\hline \multicolumn{3}{|l|}{ Cause for patients suffering treatment delay: } \\
\hline Not possible to ensure IMP supply & 0 & $0 \%$ \\
\hline Not possible to ensure safety & 0 & $0 \%$ \\
\hline Patient/parents' decision & 1 & $100 \%(1 / 1)$ \\
\hline Patients suffering treatment discontinuation & 0 & \\
\hline Units suffering restriction to perform trial assessments & 2 & $40 \%(2 / 5)$ \\
\hline Patients not being able to be recruited into potential trials & 7 & \\
\hline \multicolumn{3}{|l|}{ Alternative provided to patients not being able to be recruited into trials } \\
\hline No treatment & 3 & $43 \%(3 / 7)$ \\
\hline Out-of-trial treatment & 4 & $57 \%(4 / 7)$ \\
\hline Inclusion in a trial elsewhere & 0 & \\
\hline \multicolumn{3}{|l|}{ Decision not to include patients taken by: } \\
\hline Sponsor & 3 & $43 \%(3 / 7)$ \\
\hline Investigators & 4 & $57 \%(4 / 7)$ \\
\hline Institution & 0 & $0 \%$ \\
\hline Patient/parents & 0 & $0 \%$ \\
\hline \multicolumn{3}{|l|}{ Impact on legal aspects } \\
\hline Pending contracts postponed & 3 & \\
\hline Units approached with sponsor contingency plans for the management of issues related to the COVID-19 crisis & 5 & $100 \%(5 / 5)$ \\
\hline Units creating individual contingency plans for the management of issues related to the COVID-19 crisis & 5 & $100 \%(5 / 5)$ \\
\hline \multicolumn{3}{|l|}{ Future perspectives } \\
\hline Unit Leads expecting lower recruitment rates in 2020 compared to 2019 & 5 & $100 \%(5 / 5)$ \\
\hline Unit Leads planning changes in organization for the next months to promote home working and remote MVs or SIVs & 4 & $80 \%(4 / 5)$ \\
\hline Unit Leads thinking this crisis will make them better prepared for future crises & 5 & $100 \%(5 / 5)$ \\
\hline
\end{tabular}


sponsors and have also created individual plans for the management of COVID-19-related issues.

\section{Future perspective}

All investigators foresee a lower recruitment in 2020 compared to 2019. Most are planning changes over the next months to promote homeworking and remote SIVs/MVs. All investigators believe that this crisis will make units better prepared for future crises.

Following the analysis of this survey results and the collected expert consensus, we propose a set of recommendations to preserve patient safety, scientific integrity, and research value (Fig. 1).

\section{Conclusions}

This study reveals that paediatric cancer clinical research has been significantly impacted by the COVID-19 pandemic.

Shortage of personnel has been a major issue in all units, as a consequence of contingency plans restricting on-site work. While physicians and nurses' activities have been severely compromised as their activities are essentially patient-centred, it may have less impact on other professional strata such as study coordinators or data managers, provided that they have appropriate means to perform their work remotely. Unfortunately, this was not the case for all institutions. Providing homeworking solutions is essential under the perspective of sustained restrictions over the next months. Although redeployment of staff to other areas in the

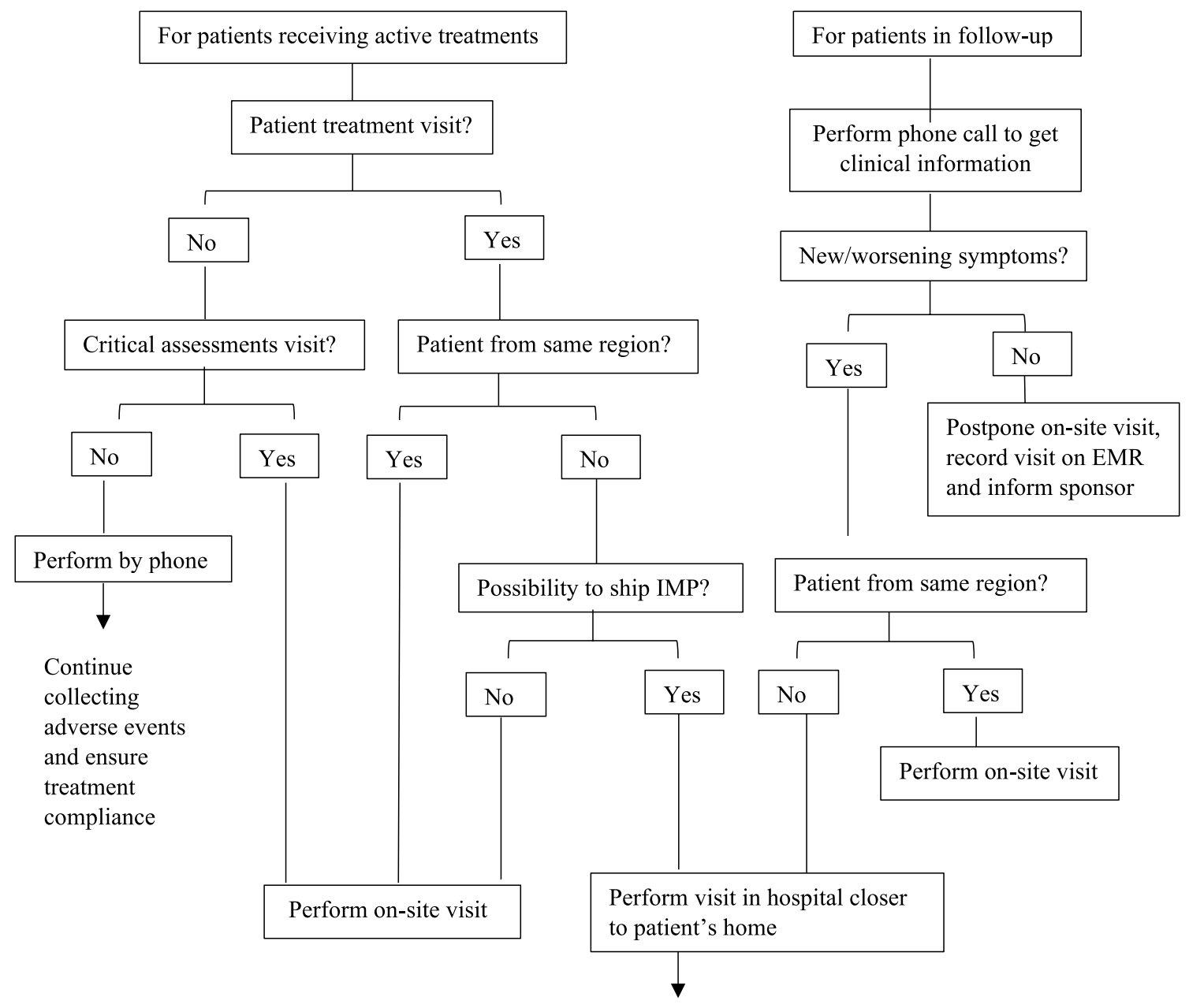

Ask sponsor to facilitate shipment of IMP

IMP: Investigational medical product

EMR: Electronic Medical Record

Fig. 1 Set of recommendations to preserve patient safety, scientific integrity and research value 
fight against COVID-19 is necessary, it has an undeniable impact on areas with highly specialized, multidisciplinary activities, as is clinical research.

Our study shows drastic suspension/delays of SIVs and MVs. Delays in SIV are understandable decisions because of the inherent complexity of early phase studies, but they need to be rescheduled as soon as possible. However, MVs are key to ensure safety and data quality of on-going trials, and hence, it is necessary that sponsors implement alternative mechanisms to resume it in collaboration with the sites while preserving patient data protection (e.g., remote access to electronic medical records with regular contacts with the study coordinators).

All units have experienced restrictions in treatment delivery or ability to conduct trial assessments. Nevertheless, all units have implemented strategies to mitigate these risks while delivering treatment to the patients, complying with trial regulations and in agreement with sponsors. The outbreak is expected to increase protocol deviations, highlighting the need for a fluid communication between sites, ethics committees, sponsors, and regulators. Regulators should take a sensible approach when reviewing these deviations, especially when the trial participant's best interest has been taken into account and no additional risk has been posed [8].

In our study, only one patient had his treatment delayed due to family's fears of travelling. While patients and caregivers are advised to restrict hospital visits, they may delay medical consultation when facing adverse events during a trial. Cortiula et al. [9] highlighted the negative implications of excessive focus on COVID-19 and of overshadowing the other aspects of clinical practice, especially in cancer care.

Only two patients could be recruited in this period, a $75 \%$ reduction in the expected recruitment rate, while seven potentially eligible patients could not be recruited. Clinical trials are most of the times the unique way to provide access to new drugs with significant patient benefit (e.g., TRK inhibitors for $T R K$-fusion cancers [14]), or at the very least, to innovative therapies to children with no curative options. Whereas COVID-19 has a low mortality in children [4], more than $90 \%$ of children with relapsed and refractory cancers will continue to die and, hence, access to novel therapies needs to be assured. Moreover, the stalling process on experimental medicines will extend the already lengthy marketing process and have an impact on the companies' market value [15]. Therefore, long-term consequences of the pandemic on clinical research remain unpredictable.

Although there are multiple publications about generic emergency preparedness in health settings, there is minimal information focusing on clinical trial sites $[16,17]$ and we provide recommendations on this respect (Fig. 1).

All consulted investigators conclude that this crisis will make trial units better prepared for future emergencies and they are planning changes in their organization.
Our results show that the COVID-19 crisis has had a major impact on conducting paediatric oncology research. Our conclusions will hopefully help investigators, sponsors, and authorities to address the issues derived from this pandemic and facilitate the construction of a consensus strategy for future crises. This would allow for maintaining highquality care, standardizing procedures, and prioritizing an efficient use of resources, to ensure safe access to therapies in the context of clinical trials.

Author contributions All authors contributed to the study conception and design. Material preparation, data collection, and analysis were performed by Alba Rubio-San-Simón and Francisco Bautista. The first draft of the manuscript was written by Alba Rubio-San-Simón and Francisco Bautista, and all authors commented on previous versions of the manuscript. All authors read and approved the final manuscript.

Funding There was no funding for this study

\section{Compliance with ethical standards}

Conflicts of interest F Bautista had a consultant or advisory role for Bayer, Amgen, Sanofi, and EusaPharma, received honoraria for speaking at symposia from Amgen and Jazz Pharmaceuticals, and support for attending symposia from Takeda, EusaPharma, Shire, and Jazz Pharmaceuticals. L Moreno had a consulting or advisory role for Novartis, AstraZeneca, Roche Genentech, Bayer, Amgen, and MundiPharma. He received honoraria from Celgene and Novartis for educational events and travel expenses from MundiPharma, Celgene, Amgen. L Moreno is a member of the Executive Committee of SIOPEN, non-profit organization that receives royalties for the sales of dinutuximab beta. A. Cañete had a consulting or advisory role for Eusa Pharma and Bayer. She received honoraria from Usa Pharma for educational events and travel expenses. A. Canete is a member of the Executive Committee of SIOPEN, non-profit organization that receives royalties for the sales of dinutuximab beta. The rest of the authors declare that they have no conflict of interest.

Ethical approval All procedures performed in studies involving human participants were in accordance with the ethical standards of the participant institutions research committes and with the 1964 Helsinki declaration and its later amendments or comparable ethical standards.

Informed consent Informed consent was obtained from all individuals participating in clinical trials.

\section{References:}

1. Coronavirus disease (COVID-19) Situation in numbers (by WHO Region) [Internet]. [cited 2020 May 5]. Available from: https:// www.who.int/docs/default-source/coronaviruse/situation-repor ts/20200504-covid-19-sitrep-105.pdf?sfvrsn=4cdda8af_2.

2. BOE.es - Documento consolidado BOE-A-2020-3692 [Internet]. [cited 2020 Apr 18]. Available from: https://www.boe.es/eli/es/ rd/2020/03/14/463/con.

3. Infection prevention and control and preparedness for COVID-19 in healthcare settings - second update [Internet]. [cited $2020 \mathrm{Apr}$ 18]. Available from: https://www.ecdc.europa.eu/en/publicatio 
ns-data/infection-prevention-and-control-and-preparedness-covid -19-healthcare-settings.

4. Ludvigsson JF. Systematic review of COVID-19 in children shows milder cases and a better prognosis than adults. Acta Paediatr. 2020.

5. Shen K, Yang Y, Wang T, Zhao D, Jiang Y, Jin R, et al. Diagnosis, treatment, and prevention of 2019 novel coronavirus infection in children: experts' consensus statement. World J Pediatr 2020.

6. Calvo C, García López-Hortelano M, de Carlos Vicente JC, Vázquez Martínez JL, Ramos JT, Baquero-Artigao F, et al. Recomendaciones sobre el manejo clínico de la infección por el «nuevo coronavirus» SARS-CoV2. Grupo de trabajo de la Asociación Española de Pediatría (AEP). An Pediatría. 2020.

7. Medidas excepcionales aplicables a los ensayos clínicos para gestionar los problemas derivados de la emergencia por COVID19 - Agencia Española de Medicamentos y Productos Sanitarios [Internet]. [cited 2020 May 5]. Available from: https://www. aemps.gob.es/informa/notasinformativas/medicamentosusohuman o-3/2020-medicamentosusohumano-3/medidas-excepcionalesaplicables-a-los-ensayos-clinicos-para-gestionar-los-problemasderivados-de-la-emergencia-por-covid-19/.

8. Guidance on the management of clinical trials during the covid-19 (coronavirus) pandemic [Internet]. [cited 2020 May 5]. Available from: https://ec.europa.eu/health/sites/health/files/files/eudralex/ vol-10/guidanceclinicaltrials_covid19_en.pdf

9. Cortiula F, Pettke A, Bartoletti M, Puglisi F, Helleday T. Managing COVID-19 in the oncology clinic and avoiding the distraction effect. Ann Oncol. 2020.

10. Liang W, Guan W, Chen R, Wang W, Li J, Xu K, et al. Cancer patients in SARS-CoV-2 infection: a nationwide analysis in China. The Lancet Oncology. 2020.

11. Chen Z, Xiong H, Li JX, Li H, Tao F, Yang YT, et al. [COVID19 with post-chemotherapy agranulocytosis in childhood acute leukemia: a case report]. Zhonghua Xue Ye Xue Za Zhi. 2020.
12. Bouffet E, Challinor J, Sullivan M, Biondi A, Rodriguez-Galindo C, Pritchard-Jones K. Early advice on managing children with cancer during the COVID-19 pandemic and a call for sharing experiences. Pediatr Blood Cancer. 2020.

13. Zwaan CM, Kearns P, Caron H, Verschuur A, Riccardi R, Boos $\mathrm{J}$, et al. The role of the "innovative therapies for children with cancer" (ITCC) European consortium. Cancer Treatment Reviews. 2010.

14. Correction: Larotrectinib for paediatric solid tumours harbouring NTRK gene fusions: phase 1 results from a multicentre, openlabel, phase 1/2 study. Lancet Oncol (2018) 19(5) (705-714) 10.1016/S1470-2045(18)30119-0

15. Paul SM, Mytelka DS, Dunwiddie CT, Persinger CC, Munos BH, Lindborg SR, et al. How to improve RD productivity: The pharmaceutical industry's grand challenge. Nature Reviews Drug Discovery. 2010.

16. McDuffie R, Summerson J, Reilly P, Blackwell C, Goff D, Kimel $\mathrm{AR}$, et al. The Action to Control Cardiovascular Risk in Diabetes (ACCORD) Trial and Hurricane Katrina: Lessons for managing clinical trials during and after a natural disaster. Contemp Clin Trials. 2008.

17. Lunt $\mathrm{H}$, Heenan $\mathrm{H}$. Mitigating the impact of disasters and emergencies on clinical trials site conduct: A site perspective following major and minor unforeseen events. Contemp Clin Trials Commun. 2019.

Publisher's Note Springer Nature remains neutral with regard to jurisdictional claims in published maps and institutional affiliations. 